edition. Canberra: Commonwealth Department of Human Services and Health, 1995.

2. Australian Bureau of Statistics. Australian social trends, 2000. Canberra: ABS, 2000; 73-76.

3. Butler T. New South Wales Prison Inmates' Health Survey. Sydney: Corrections Health Service, 1997.

4. Edwards R, Brown JS, Hodgson P, Reed D, Wallace B. An action plan for tobacco control at the regional level. Public Health 1999; 113: 165-170.

5. NSW Department of Health. Tobacco and Health Strategy, 1995-1999. Sydney: NSW Department of Health, 1995.

6. Commonwealth Department of Health and Aged Care. National Tobacco Strategy, 1999 to 2002-2003: A framework for action. Canberra: Commonwealth Department of Health and Aged Care, 1999.

7. Awofeso N. Controlling tobacco use in prisons. Int J Tuberc Lung Dis 1999; 3: 547-8.
8. Awofeso N. Tobacco control in New South Wales Prisons: Translating Advocacy into Programs and Change. 12th Health Promotion Conference, Melbourne, October 2000 (unpublished).

9. Awofeso N, Testaz R, Wyper S, Morris S. Smoking prevalence in New South Wales prisons, 2000. Tobacco Control, 2001; 10: 84-5.

10. Department of Corrective Services. Smoke-Free Work Environment (Correctional Facilities) Policy, 17 May 1989, Sydney (unpublished).

11. Klesges RC, Haddock CK, Chang CF, Talcott WG, Lando HA. The association of smoking and the cost of military training. Tobacco Control 2001; 10: 43-47.

12. Hughes JR. Why does smoking so often produce dependence? A somewhat different view. Tobacco Control 2001; 10: 62-64.

13. Editorial. Cigarette smoking bans in county jails-Wisconsin, 1991. MMWR 1992; 41: 101-3.

\title{
IDENTIFYING WORK-RELATED INJURY AND DISEASE IN ROUTINELY COLLECTED NSW HOSPITALISATION DATA
}

\section{David Muscatello \\ Epidemiology and Surveillance Branch NSW Department of Health}

\section{Rebecca Mitchell}

Health Promotion Branch

NSW Department of Health

Occupational disease and injury has been estimated to account for nearly three per cent of the global burden of disease. ${ }^{1}$ In NSW in the 1998-99 financial year, there were 38,069 workers' compensation cases reported to the National Occupational Health and Safety Commission. However, this figure is an under-estimation of the true incidence of occupational disease and injury in NSW, because it includes only cases resulting in compensation under NSW workers' compensation legislation, it only includes cases involving absences from work of five days or more, and because self-employed people are not generally covered for workers' compensation. ${ }^{2}$ This article describes an analysis of the NSW Inpatient Statistics Collection (ISC) to identify work-related hospitalisations, and comments on its potential for monitoring occupational disease and injury in NSW.

\section{METHODS}

The NSW ISC is a census of separations from NSW public and private hospitals, which is routinely collected by the NSW Department of Health. Clinical coders at each hospital or health service code medical record information for each hospital admission episode and enter the data into a database that is periodically uploaded to the central data repository held at the NSW Department of Health. Information collected includes patient demographics, payment status, diagnoses and clinical procedures. External causes are recorded for hospitalisations following injury or poisoning and can be recorded for other conditions.

For the period used for this analysis (1999-00 financial year), diagnoses, external causes and procedures in the ISC were coded according to the International Statistical Classification of Diseases and Related Health Problems, 10th Revision, Australian Modification (ICD-10-AM), first edition. ${ }^{3}$ In the first edition of the ICD-10-AM, the fifth character of the ICD code for external cause classifies the activity being undertaken by the patient when the injury or illness occurred. An activity code of ' 2 ' indicates 'working for income'. ${ }^{3}$ A principal diagnosis and up to 20 additional diagnoses were coded, and up to three external causes could be coded.

A fourth character was also available for coding in the ICD-10-AM (1st edition) to code the place where the injury or illness occurred. We did not use this fourth character because it only identifies a subset of workrelated places, such as industrial or construction areas. It does not permit identification of whether the person was engaged in a work-related activity at that place, and it is possibly less likely to be noted on the medical record than the activity the person was engaged in.

Hospital separations from the 1999-00 financial year ISC database were identified as occupationally related if they had any of:

- a first external cause coded combined with an activity when injured of 'working for income' (ICD-10-AM 
codes starting with ' $\mathrm{V}$ ', 'W', ' $\mathrm{X}$ ' or ' $\mathrm{Y}$ ' and a ' 2 ' as the activity code);

- a payment status indicating workers' compensation;

- an ICD-10-AM code of 'Z04.2' ('Examination and observation following work accident') in any of the principal or other diagnoses;

- an ICD-10-AM code of 'Z57' ('Occupational exposure to risk factors') in any of the principal or other diagnoses;

- an ICD-10-AM code of 'Y96' ('Work-related condition') in any of the three external cause codes. ${ }^{4}$

At the time of analysis, the ISC data for 1999-00 did not include data for NSW residents hospitalised in other states. Non-residents of NSW admitted to NSW hospitals were excluded.

\section{RESULTS}

There were 10,608 hospitalisations of NSW residents in 1999-00 that were identified as being work-related, with 85 per cent occurring in men. Six per cent of hospitalisations were in workers aged under 20 years, 36 per cent were aged 20-34 years, 35 per cent were aged 35-49 years, 20 per cent were aged 50-64 years, and three per cent were aged 65 years and over. Of hospitalisations with any indication of being work-related, the majority (96 per cent) were identified by examining the activity code associated with the first external cause code (Table 1).

The most common principal diagnoses among hospitalisations identified as being work-related were open wounds, fractures and muscular or tendon injuries of the wrist or hand (19 per cent), followed by back pain (5 per cent) (Table 2). The most common external causes of injury or other conditions were unknown in 10 per cent of hospitalisations, related to overexertion, strenuous or repetitive movements in another 10 per cent, and machinery-related (excluding mobile machinery) in nine per cent (Table 3). Among hospitalisations not assigned an injury principal diagnosis (ICD-10-AM codes beginning with ' $S$ ' or ' $T$ '), the diagnoses were likely to be largely injury-related but falling under other diagnosis groups in the ICD-10-AM (Table 4).
Among hospitalisations with a cause of overexertion, strenuous or repetitive movements, the most common principal diagnoses were back pain (17 per cent), dislocation, sprain and strain of joints and ligaments of the knee (12 per cent), and inguinal hernia (11 per cent). Among those with a cause of other and unspecified machinery, the most common principal diagnoses were traumatic amputation of part or all of the hand or fingers (21 per cent), open wounds of the wrist, hand or fingers (19 per cent), and fractures of the wrist, hand or fingers (17 per cent).

\section{DISCUSSION}

This analysis demonstrates that hospitalisations as a result of work-related injury and disease can be identified using the NSW ISC. Injuries of the hand, back and knee are the most commonly identified work-related conditions requiring hospitalisation in NSW, and that overexertion, repetitive or strenuous movements and machinery are the most commonly identified factors leading to work-related hospitalisation. This information can supplement the information collected using more selective criteria in other data collections such as the Workers' Compensation collection.

Identification of work-related hospitalisations in the ISC depends on whether the patient reported relevant information, whether an occupational link was clinically identified, and the completeness of medical records. Based on this analysis, the sensitivity and specificity of the ISC for determining work-related diseases and injuries cannot be determined. Other limitations include the possibility of multiple counting of patients due to multiple admissions of the same patient during the period of study, and the inability to identify the occupations or industries involved. Coding accuracy is unlikely to be a serious concern. Victorian hospital coding validation studies have found low percentages of coding error, with only six per cent of principal diagnoses to be in error at the threecharacter level and 22 per cent at any level; ${ }^{5}$ and only 16 per cent of external cause codes containing an error. ${ }^{6}$

Traditionally, data on occupation-related disease have not been well covered in Australia, ${ }^{7-9}$ with the exception of

\section{TABLE 1}

WORK-RELATED HOSPITALISATIONS BY METHOD OF IDENTIFICATION, NSW, 1999-00

\begin{tabular}{|lrr|}
\hline Method of identification & No. & \% (N=10,608) \\
\hline First external cause with an activity of working for income & 10,214 & 96.3 \\
Principal diagnosis is Z04.2: Examination/observation following work accident & 2 & 0.0 \\
Principal diagnosis is Z57: Occupational exposure to risk factors & 3 & 0.0 \\
Other diagnosis is Z04.2: Examination/observation following work accident & 202 & 0.0 \\
Other diagnosis is Z57: Occupational exposure to risk factors & 126 & 1.9 \\
Any external cause code is Y96: Work-related condition & 156 \\
Payment status is workers' compensation & 1.2 \\
\hline Note:Percentages do not add to 100 per cent because a hospitalisation can exhibit more than one indication of \\
being work-related. Totals were excluded for this reason.
\end{tabular}




\section{TABLE 2}

TEN MOST COMMON PRINCIPLE DIAGNOSES AMONG WORK-RELATED HOSPITALISATIONS, NSW, 1999-00

\begin{tabular}{|lcc|}
\hline Principal Diagnosis (ICD-10-AM code) & No. & \% (N=10,608) \\
\hline Open wound of wrist and hand (S61) & 786 & 7.4 \\
Fracture in wrist, hand or fingers (S62) & 688 & 6.5 \\
Injury of muscle and tendon in wrist, hand or fingers (S66) & 562 & 5.3 \\
Dorsalgia (back pain) (M54) & 550 & 5.2 \\
Dislocation, sprain or strain of joints and ligaments of knee (S83) & 537 & 5.1 \\
Traumatic amputation of fingers or hand (S68) & 503 & 4.7 \\
Fracture of forearm (S52) & 423 & 4.0 \\
Fracture of lower leg, including ankle (S82) & 409 & 3.9 \\
Internal derangement of knee (M23) & 201 & 1.9 \\
Fracture of foot, excluding ankle (S92) & 199 & 1.9 \\
\hline Total & 4,858 & 45.9 \\
\hline
\end{tabular}

\section{TABLE 3}

TEN MOST COMMON EXTERNAL CAUSES OF INJURY, POISONING OR OTHER CONDITIONS AMONG WORK-RELATED HOSPITALISATIONS, NSW, 1999-00

\begin{tabular}{|lrc|}
\hline External cause (ICD-10-AM code) & No. & \% (N=10,608) \\
\hline Exposure to unspecified factor (X59) & 1,066 & 10.2 \\
Overexertion and strenuous or repetitive movements (X50) & 1,023 & 9.8 \\
Contact with other or unspecified machinery (W31) & 950 & 9.1 \\
Struck by thrown, projected or falling object (W20) & 500 & 4.8 \\
Caught, crushed, jammed or pinched in or between objects (W23) & 494 & 4.7 \\
Striking against or struck by object (not sports equipment, projected, & 424 & 4.1 \\
$\quad$ or falling objects) (W22) & 399 & 3.8 \\
Fall on same level from slipping, tripping or stumbling (W01) & 386 & 3.7 \\
Contact with other powered hand tools and household machinary & & \\
(not lawnmower) (W29) & 374 & 3.6 \\
Foreign body or object entering through skin (W45) & 335 & 3.2 \\
Contact with knife, sword or dagger (W26) & 5,951 & 57.0 \\
\hline Total & \\
\hline
\end{tabular}

\section{TABLE 4}

TEN MOST COMMON NON-INJURY PRINCIPAL DIAGNOSES AMONG WORK-RELATED HOSPITALISATIONS, NSW, 1999-00

\begin{tabular}{|lrr}
\hline Princiapl diagnosis (ICD-10-AM code) & No. & \% (N=2,436) \\
\hline Dorsalgia (back pain) (M54) & 550 & 22.6 \\
Internal derangement of knee (M23) & 201 & 8.3 \\
Inguinal hernia (K40) & 159 & 6.5 \\
Care involving use of rehabilitation procedures (Z50) & 123 & 5.0 \\
Other joint disorders, not elsewhere classified (M25) & 120 & 4.9 \\
Shoulder lesions (M75) & 99 & 4.1 \\
Mononeuropathies of upper limb (G56) & 89 & 3.7 \\
Other intervertebral disc disorders (M51) & 87 & 3.6 \\
Cellulitis (L03) & 78 & 3.2 \\
Gonarthrosis (arthrosis of the knee) (M17) & 61 & 2.5 \\
\hline Total & 1,567 \\
\hline Note: 'Non-injury' was classified as ICD-10-AM diagnoses other than those starting with 'S' or 'T'
\end{tabular}


the National Occupational Health and Safety Commission Mesothelioma Register. Occupational health and safety (OHS) and workers' compensation agencies have been the main source of information, but underenumeration of work-related conditions by Australian workers' compensation data has been estimated at between 35 and 57 per cent. ${ }^{7,10-12}$ The NSW ISC may provide information that can complement other data sources as it has the advantage of including all workers hospitalised due to injury, regardless of their employment arrangements. Injury-related conditions overshadowed other conditions in our analysis; a more restrictive analysis may provide useful information about non-injury conditions.

Users of Australian ISC data should be aware that from July 2000, with the introduction of the second edition of the ICD-10-AM, the activity associated with an external cause was coded using a separate external cause code, 'Y93', whereas previously this was coded into the fifth character of the cause code as used in this study. ${ }^{13}$ Also, NSW ISC data may have more complete recording of workers' compensation cases from July 2000, following identification of problems with recording of payment status (NSW Department of Health, personal communication). The planned future introduction of unique patient identifiers in NSW will address the issue of multiple counting of patients.

In conclusion, the ISC offers an indication of the relative frequency and pattern of work-related injuries and diseases and their causes, thereby providing a guide to prevention of work-related injury and perhaps disease. Unexpected patterns of injury or disease may highlight areas where further research is required. Based on this analysis, prevention and research activities should include hand protection, and safe methods of strenuous or repetitive movement to prevent back and knee injuries and inguinal hernias as well as safe use of machinery.

\section{ACKNOWLEDGMENTS}

The assistance of Susan Travis, Manager of the NSW Births Defects Register, Epidemiology and Surveillance Branch, in selecting ICD-10-AM codes for analysis is gratefully acknowledged.

\section{REFERENCES}

1. Leigh J, Macaskill P, Kuosma E, Mandryk J. Global burden of disease and injury due to occupational factors. Epidemiology 1999; 10: 626-631.

2. National Occupational Health and Safety Commission. National, State and Territory Workers' Compensation Statistical Tables [cited April 18 2001]. URL: www.worksafe.gov.au/databases/compsuptables/main.html.

3. National Centre for Classification in Health. The International Statistical Classification of Diseases and Related Health Problems, 10th Revision, Australian Modification (ICD-10$A M)$. Sydney: National Centre for Classification in Health, 1998.

4. Epidemiology and Surveillance Branch. Health Outcomes and Information Statistical Toolkit (HOIST). Sydney: NSW Department of Health [Computer program].

5. MacIntyre CR, Ackland MJ, Chandraraj EJ. Accuracy of ICD9-CM codes in hospital morbidity data, Victoria: implications for public health research. Aust NZ J Public Health 1997; 21 : 477-82.

6. MacIntyre CR, Ackland MJ, Chandraraj EJ. Accuracy of injury coding in Victorian hospital morbidity data. Aust NZJ Public Health 1997; 21: 779-82.

7. National Occupational Health and Safety Commission. National Occupational Health and Safety Improvement Framework: Report 2000. Sydney: National Occupational Health and Safety Commission, 2000.

8. Department of Epidemiology and Preventive Medicine, Monash University. Stocktake of Australian Data Sources of Occupational Disease. Melbourne: Monash University, 2000.

9. Wigglesworth EC. The current hiatus in occupational injury research in Australia. Aust NZ J Public Health 2001; 25: 94-97.

10. Driscoll T, Mitchell R, Mandryk J, Healey S, Hendrie L, Hull B. Work-related fatalities in Australia, 1989 to 1992: an overview. Journal of Occupational Health and SafetyAustralia and New Zealand 2001; 17 (1): 45-66.

11. Mitchell R, Mandryk, J. The 1995 Australian Workplace and Industrial Relations Survey (AWIRS 95): An Occupational Health and Safety Perspective. Sydney: National Occupational Health and Safety Commission, 1998.

12. National Occupational Health and Safety Commission. Workrelated Aspects of Patient Presentations to General Practitioners: Analysis of the First 12 Months of BEACH Data. Sydney: National Occupational Health and Safety Commission, 2000.

13. National Centre for Classification in Health. The International Statistical Classification of Diseases and Related Health Problems, 10th Revision, Australian Modification (ICD-10$A M$, Second Edition). Sydney: National Centre for Classification in Health, 2000.

\section{MEN FULLY ALIVE AND BUILDING SPIRIT: BUILDING HEALTH NATIONAL MEN'S AND BOY'S HEALTH CONFERENCE AND NATIONAL INDIGENOUS MALE HEALTH CONVENTION}

Men Fully Alive, the 4th National Men's and Boy's Health Conference, will be held over the period 26-29 September 2001 at the Hawkesbury Campus of the University of Western Sydney. The Conference will support and celebrate programs and research that build on boys' and men's health and wellbeing.

Building Spirit : Building Health, the 2nd National Indigenous Male Health Convention, will be held in the same location just prior to the Conference. There will be a crossover of information between the mainstream Conference and the Convention. Indigenous men will appoint a delegation to inform the mainstream Conference about the highlights of the Convention.

For more information, or to register a place at the Conference or Convention, visit the Web site at; www.menshealth.uws. edu.au; or contact the Men's Health Information and Resource Centre by telephone at (02) 45701713 , or by email at menshealth@uws.edu.au. Alternately, contact the Conference Secretariat by telephone at (02) 4570 1690, or by email at a.campbell@uws.edu.au. 